\title{
Multi Criteria Decision Making to Select the Suitable Method for the Preparation of Nanocrystals Using an Analytic Hierarchy Process
}

\author{
Venkatesh Kyavars, Selvamuthukumar Subramanian* \\ Department of Pharmacy, Faculty of Engineering and Technology, Annamalai University, Annamalai Nagar, Tamilnadu, INDIA.
}

\begin{abstract}
Purpose: This paper presents a systematic approach for selecting the right method for the preparation of nanocrystals. Aim: The aim of this paper is to provide an analytical tool to select the most appropriate method for the preparation of nanocrystals. Method: The tool that can be useful in determining the most appropriate method is the Analytic Hierarchy Process (AHP). One of the main advantages of this method is the relative ease with which it handles multiple criteria. In addition to this, AHP is easier to understand and it can effectively handle both qualitative and quantitative data. AHP involves the principles of pairwise comparisons, priority vector generation and synthesis. Results: The overall priorities of the subcriteria with respect to the criteria for each method are given and Method M2 Sonoprecipitation method scored 0.263, M4 Nanomorph ${ }^{\circledR}$ method scored $0.258, \mathrm{M} 1 \mathrm{Hydrosol}$ method scored 0.239 and finally M3 Spray freezing into liquid (SFL) method scored 0.225 . The alternative with the highest priority would achieve the goal as per Saaty. Hence, having worked out the AHP technique, the Sonoprecipitation method is judged to be the most suitable method for the preparation of nanocrystals. Conclusion: In this paper, AHP has been employed to capture the decision making process to provide reliable and efficient decision. Hence we can obtain consistent and best preferred decision easily and efficiently by using this tool.
\end{abstract}

Key words: Sonoprecipitation, Nanocrystals, Bioavailability enhancement, MCDM, Analytic Hierarchy Process.

\section{INTRODUCTION}

Formulation of drug carrier systems, development of diagnostic tools and gene therapy are the novel applications of nanotechnology in pharmaceutical field. ${ }^{1}$ Nano drug delivery systems are nanoparticles, nanosponges, nanospheres, solid lipid nanoparticles, nanoemulsions, molecular system (inclusion complexes), nanovesicular system (Liposome, niosomes), and Nanocrystals. ${ }^{2}$ Among the above one of the most effective drug delivery system is nanocrystal. The composition of nanocrystal is active pharmaceutical ingredient (API), water and stabilizer. This stabilizer prevent reaggregation of API due to which nanocrystals are physically stable and good physical stability is expected because crystalline state is more stable than the amorphous state. Freeze drying is done immediately after nanocrystal production to improve physical stability and also to prevent their agglomeration. ${ }^{3,4}$

Nanocrystals are crystals having size less than $1 \mu \mathrm{m}$. As the particle size of crystals is decreased to about $100 \mathrm{~nm}$ there is a drastic change in the properties of the material. The decreased size increases the surface area and solubility of drug manifolds and there is fair increase in the bioavailability of poorly soluble drug. ${ }^{5}$ Nanocrystals enhance the solubility of poorly soluble or insoluble drugs. ${ }^{6}$ In the current drug delivery technology platform, drug nanocrystals play a major and distinctive role which lead to extensive utilization of the nanocrystal approch. ${ }^{7}$
Submission Date: 30-08-2016; Revision Date: 17-11-2016; Accepted Date: 23-11-2016

DOI: $10.5530 / \mathrm{ijper} .51 .2 .30$ Correspondence: Selvamuthukumar Subramanian, Department of Pharmacy, Faculty of Engineering and Technology, Annamalai University, Annamalai Nagar - 608 002, Tamilnadu, India Ph no: 9843675681

E-mail: smk1976@gmail.com

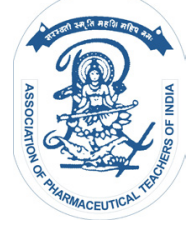

www.ijper.org 
Superior solubility and dissolution rate, enhanced bioavailability, safe dose acceleration, eradication of food effects, better safety and efficacy are some of the advantages of drug nanocrystals. ${ }^{8}$ Bioavailability of Class II/ IV drugs in the bio-pharmaceutical classification system can be enhanced by drug nanocrystals. ${ }^{9}$ The condensed diameter can boost the solubility and dissolution rate of a drug, which allows elevated concentration gradient diffusion, ${ }^{10}$ at the same time an increased adhesion to the mucous membrane in the gastrointestinal tract prolongs the drug retention and absorption time. ${ }^{11}$

Nanocrystal formulation throughs a new light in sophisticated drug development because for particular diseases like cancer, nanocrystals are known to be novel drug delivery system because of its potential to administer through various routes and also its ease of preparation. ${ }^{12}$ Nanocrystals present an opportunity to take advantage of other cellular uptake processes such as endocytosis to utilize the potential for targeted drug delivery. ${ }^{13}$ The crystals were analyzed for particle size, powder X-ray diffraction and dissolution. ${ }^{14}$

As nanocrystal technology is an emerging field, there is an urge for production of nanocrystals from lab scale to large scale. ${ }^{15}$ A number of methods are used for preparation of nanocrystals which includes sonoprecipitation, hydrosol, high pressure homogenization, spray freezing into liquid, milling and nanomorph ${ }^{\circledR} .{ }^{16}$ So we have decided to use a decision making tool such as analytic hierarchy process to select the best method. ${ }^{17}$

\section{Analytic Hierarchy Process}

Analytic Hierarchy Process (AHP) is one of the most useful tool for method selection which was developed by Saaty at the Wharton School of Business. ${ }^{18}$ This is a significant and flexible weighted scoring decision making process to make the most excellent decision by setting priorities. ${ }^{19}$

The AHP developed by Saaty ${ }^{20}$ is a decision approach design and has successfully been used in a wide variety of application domains. In AHP the decision problem is arranged in the form of hierarchy where overall goal, criteria, sub-criteria and decision alternatives are arranged from top to lowest level.

\section{AHP Approach}

Basically, AHP is a multiobjective and multicriteria decision making approach that employs a pairwise comparison procedure to arrive at a scale of preferences among a set of alternatives. In this approach, it is essential to split down a composite unstructured problem into its section parts and put these parts or variables into a hierarchic order, allot numerical values to our judgments on the relative importance of each variables and synthesize the judgments to find out which variables have the highest priority and should be acted upon to influence the outcome. The matrix derived from the pairwise comparison using a nine-point scale is called comparison or judgment matrix and it also consists of eigen vector method for deriving weights and consistency. ${ }^{21}$

\section{RESULTS AND DISCUSSION}

\section{Analytic hierarchy process principles}

AHP consists of three main principles that is hierarchy framework, priority analysis and consistency verification. ${ }^{18,22,23}$ The initial step of AHP is formulating the decision problem in the form of a hierarchy framework where overall objective is represented at the top level, criteria and sub-criteria at the middle level and decision alternatives at the lowest level. After constructing hierarchy framework, at each hierarchy a pairwise comparison matrix is to set up by using a scale pairwise comparison and compare options as shown in Table 1. In the priority stage synthesis, to determine the performance of alternatives and importance of the criteria an eigenvector method is used to solve each comparison matrix. ${ }^{23}$ The whole process of AHP is shown in Figure 1 which consists of nine steps.

\section{AHP at the conceptual design stage - case study}

In the product development process normally there are six stages and conceptual design is one among it. This design consists of three processes, namely concept evaluation, concept generation and concept development. In this paper only concept selection or evaluation is discussed. So in order to select the most appropriate method for the preparation of nanocrystals, the following AHP steps, as listed in Figure 1, must be considered:

\section{Step 1: Define the problem}

To select the best method for the preparation of nanocrystals. After performing several steps for method selection, there are four possible methods as listed below. So it is necessary to select the apt method by using AHP: M1 Hydrosol, M2 Sonoprecipitation, M3 Spray freezing into liquid, M4 Nanomorph ${ }^{\circledR}$.

\section{Step 2: Develop a hierarchy model}

In this step, a four level hierarchy model to select the best method using AHP is shown in Figure 2.

\section{Level I}




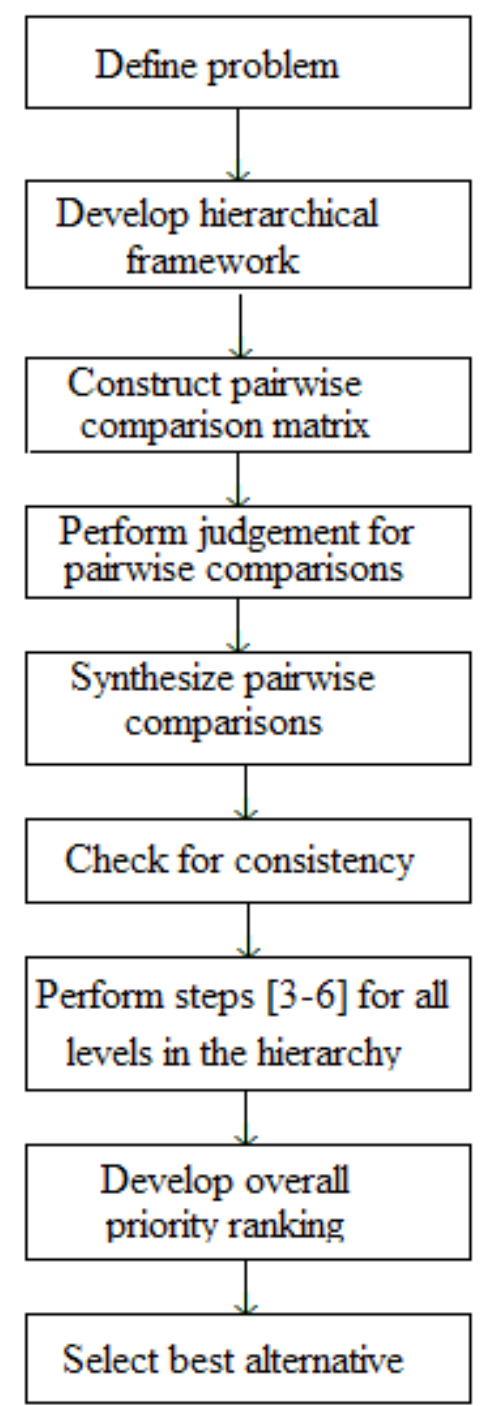

Figure. 1: Steps of the Analytic hierarchy process (AHP).

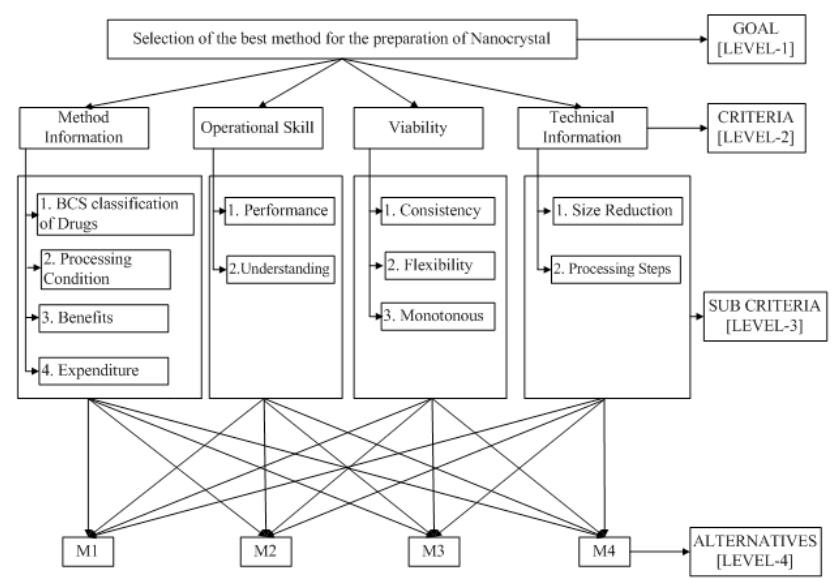

Figure 2: Hierarchy model for selection of the best method for the preparation of nanocrytals.
The overall goal, that is to 'select the suitable method for the preparation of nanocrystals' is presented at the top level of the hierarchy.

\section{Level II}

The main criteria that will help to reach the goal are represented here and the main criteria are Method Information (MI), Operational Skill (OS), Viability(VI), and Technical Information (TI).

\section{Level III}

Here sub-criteria are represented and there are four sub-criteria that refer to Method information: BCS (Biopharmaceutical Classification system) Classification of drugs (BCS), Processing conditions (PC), Benefits (BE) and Expenditure (EX). Performance (PR) and Understanding (UN) add value for Operational Skill. Consistency (CO), Flexibility (FX) and Monotonous (MO) are the subcriteria that add values to Viability. Size reduction (SR) and Processing steps (PS) are the subcriteria that add values to Technical Information respectively.

\section{Level IV}

At this level the alternative methods (M) for preparation of nanocrystals are identified which are the decision options: M1 Hydrosol, M2 Sonoprecipitation, M3 Spray freezing into liquid and M4 Nanomorph ${ }^{\circledR}$.

\section{Step 3: Construct a pairwise comparison matrix}

In AHP, pairwise comparisons are made to get exact ratio scale priorities. A pairwise comparison matrix (size $\mathrm{n} \times \mathrm{n}$ ) is constructed for the lower levels with one matrix in the level immediately above. For each level of hierarchy, pairwise comparisons generate a matrix of relative rankings. The number of matrices depends on the number of elements at each level.

At each level, the order of the matrix depends on the number of elements at the lower level that it links to.

\section{Step 4: Perform judgment for pairwise comparison}

Pairwise comparison starts by comparing the relative importance of two selected items. There are $n \times(n-1)$ judgments necessary to develop the set of matrices in step 3. By using the scale pair wise comparison as shown in Table 1, decision makers have to judge each element. The judgments are made on the basis of decision makers experience and knowledge. For example, when making pairwise comparisons as shown in Table 2, if Method Information (MI) is strongly more important or essential than Viability (VI), then $A=5$. To each pairwise comparison reciprocals are automatically assigned.

\section{Step 5: Synthesizing the pairwise comparison}




\begin{tabular}{|c|c|c|}
\hline Relative intensity & Definition & Explanation \\
\hline 1 & Equal value & Two requirements are of equal value \\
\hline 3 & Slightly more value & Experience slightly favours one requirement over another \\
\hline 5 & Essential or strong value & Experience strongly favours one requirement over another \\
\hline 7 & Very strong value & $\begin{array}{l}\text { A requirement is strongly favoured and its dominance is } \\
\text { demonstrated in practice }\end{array}$ \\
\hline 9 & Extreme value & $\begin{array}{l}\text { The evidence favouring one over another is of the highest } \\
\text { possible order of affirmation }\end{array}$ \\
\hline $2,4,6,8$ & $\begin{array}{l}\text { Intermediate values between two adjacent } \\
\text { judgements }\end{array}$ & When compromise is needed \\
\hline Reciprocals & & Reciprocals for inverse comparison \\
\hline
\end{tabular}

\begin{tabular}{|c|c|c|c|c|}
\hline & $\begin{array}{c}\text { Table 2: Pairwise comparison of criteria with respect } \\
\text { to overall goal }\end{array}$ \\
\hline Goal & MI & OS & VI & TI \\
\hline Method Information (MI) & 1 & 3 & $\mathrm{~A}=5$ & 5 \\
\hline Operation Skill (OS) & $1 / 3$ & 1 & 3 & 3 \\
\hline Viability (VI) & $1 / 5$ & $1 / 3$ & 1 & 3 \\
\hline $\begin{array}{c}\text { Technical } \\
\text { Information(TI) }\end{array}$ & $1 / 5$ & $1 / 3$ & $1 / 3$ & 1 \\
\hline Total Column & 1.73 & 4.66 & 9.33 & 12 \\
\hline
\end{tabular}

\begin{tabular}{|c|c|c|c|c|c|c|c|c|c|}
\hline \multicolumn{10}{|c|}{ Table 3: Calculation to obtain new vector } \\
\hline & 1 & & 3 & & 5 & & 5 & & 2.308 \\
\hline 0.549 & $1 / 3$ & 0.248 & 1 & 0.129 & 3 & 0.074 & 3 & $=$ & 1.040 \\
\hline & $1 / 5$ & & $1 / 3$ & & 1 & & 3 & & 0.542 \\
\hline & $1 / 5$ & & $1 / 3$ & & $1 / 3$ & & 1 & & 0.308 \\
\hline
\end{tabular}

Analytic hierarchy process tool has been used to calculate priority vectors.

\section{Step 6: Perform consistency verification}

When judgments are made a degree of inconsistency can occur. So to avoid inconsistency, consistency verification is done by computing the consistency ratio. Consistency is determined by the consistency ratio (CR). Consistency ratio (CR) is the ratio of consistency index (CI) to random index (RI) for the same order matrices. $\mathrm{CR}$ can be calculated in three steps as shown:

\section{First: calculate the Eigenvalue $\left(\lambda_{\max }\right)$}

Eigenvalue $\left(\lambda_{\max }\right)$ can be calculated by multiplying the right of judgment matrix by the priority vector or eigenvector to obtain a new vector. In Table 3 it is clearly shown how to calculate a new vector. In the matrix, the calculation of first row is as shown:

$0.549(1)+0.248(3)+0.129(5)+0.074(5)=2.308$

Then divide the new vector by respective priority vector element

$2.308 / 0.549=4.20 ; 1.040 / 0.248=4.19 ; 0.542 / 0.129=$ $4.20 ; 0.308 / 0.074=4.16$.

Average the all above values to get $\lambda_{\max }$

$\lambda_{\max }=(4.20+4.19+4.20+4.16) / 4=4.18$

\section{Second: Calculate the consistency index (Cl)}

$\mathrm{CI}=\left(\lambda_{\max }-\mathrm{n}\right) /(\mathrm{n}-1)$

Where $\mathrm{n}$ is the matrix size.

\section{$\mathrm{CI}=(4.18-4) /(4-1)=0.06$}

\section{Finally: calculate the consistency ratio (CR)}

The formula used for calculating $\mathrm{CR}$ is, $\mathrm{CR}=\mathrm{CI} / \mathrm{RI}$.

First select the value of random index (RI), using table 4 for a matrix size of four. Then

$\mathrm{CR}=\mathrm{CI} / \mathrm{RI}=0.06 / 0.9=0.06$.

Judgments are accepted only if CR $<0.1$ and if CR $>0.1$ it shows inconsistency in the judgment matrix. Judgments must be reviewed to get consistent matrix. In Table 5, results for this calculation are shown.

Step 7: Steps 3-6 are performed for all levels in the hierarchy model.

\begin{tabular}{|c|c|c|c|c|c|c|c|c|c|c|c|c|}
\hline \multicolumn{10}{c|}{ Table 4: Random index of analytic hierarchy process } \\
\hline $\begin{array}{c}\text { Size of } \\
\text { matrix }\end{array}$ & 1 & 2 & 3 & 4 & 5 & 6 & 7 & 8 & 9 & 10 & 11 & 12 \\
\hline $\begin{array}{c}\text { Random } \\
\text { index(RI) }\end{array}$ & 0 & 0 & 0.58 & 0.9 & 1.12 & 1.24 & 1.32 & 1.41 & 1.45 & 1.49 & 1.51 & 1.58 \\
\hline
\end{tabular}




\begin{tabular}{|c|c|c|c|c|c|c|c|}
\hline \multicolumn{7}{|c|}{ Table 5: Consistency test for criteria } \\
\hline Goal(G) & MI & OS & VI & TI & Priority vector(PV) & New vector(NV) & NV/PV \\
\hline MI & 1 & 3 & 5 & 5 & 0.549 & 2.308 & 4.20 \\
\hline OS & $1 / 3$ & 1 & 3 & 3 & 0.248 & 0.542 & 4.19 \\
\hline VI & $1 / 5$ & $1 / 3$ & 1 & 3 & 0.129 & 0.308 & 4.16 \\
\hline TI & $1 / 5$ & $1 / 3$ & $1 / 3$ & 1 & 0.074 & Total=16.75 \\
\hline
\end{tabular}

Maximum eigen value=4.18. Consistency index $\mathrm{Cl}=0.06$. Consistency ratio $\mathrm{CR}=\mathrm{Cl} / \mathrm{RI}=0.06$.

The consistency test has been performed for all levels in the hierarchical model that are listed in Table 6 - Table 21.

\begin{tabular}{|c|c|c|c|c|c|c|c|}
\hline \multicolumn{8}{|c|}{ Table 6: Consistency test for sub-criteria } \\
\hline G/MI & BCS & PC & BE & EX & Priority vector(PV) & New vector(NV) & NV/PV \\
\hline BCS & 1 & 3 & 3 & 5 & 0.508 & 2.131 & 4.19 \\
\hline PC & $1 / 3$ & 1 & $1 / 3$ & 3 & 0.151 & 0.633 & 4.19 \\
\hline BE & $1 / 3$ & 3 & 1 & 3 & 0.265 & 0.112 & 4.19 \\
\hline EX & $1 / 5$ & $1 / 3$ & $1 / 3$ & 1 & 0.075 & Total=16.75 & 4.18 \\
\hline & & & & & & 0.314 & \\
\hline
\end{tabular}

Maximum eigenvalue $=4.18$. Consistency index $(\mathrm{Cl})=0.06$. Consistency ratio $(\mathrm{CR})=0.06$.

\begin{tabular}{|c|c|c|c|c|c|}
\hline \multicolumn{5}{|c|}{ Table 7: Consistency test for sub-criteria } \\
\hline G/OS & PR & UN & Priority vector(PV) & New vector(NV) & NV/PV \\
\hline PR & 1 & 5 & 0.833 & 0.668 \\
\hline UN & $1 / 5$ & 1 & 0.167 & 0.333 & Total=3.996 \\
\hline
\end{tabular}

Maximum eigenvalue $=1.998$ Consistency index $(\mathrm{Cl})=0.000$ Consistency ratio $(C R)=0.000$.

\begin{tabular}{|c|c|c|c|c|c|c|}
\hline \multicolumn{9}{|c|}{ Table 8: Consistency test for sub-criteria } \\
\hline G/VI & CO & FX & MO & Priority vector(PV) & New vector(NV) & NV/PV \\
\hline CO & 1 & 3 & 5 & 0.637 & 1.936 & 3.039 \\
\hline FX & $1 / 3$ & 1 & 3 & 0.258 & 0.785 & 3.042 \\
\hline MO & $1 / 5$ & $1 / 3$ & 1 & 0.105 & 0.318 & 3.028 \\
\hline & & & & & Total=9.109 \\
\hline
\end{tabular}

Maximum eigenvalue $=3.036$ Consistency index $(C l)=0.018$ Consistency ratio $(C R)=0.02$.

\begin{tabular}{|c|c|c|c|c|c|}
\hline \multicolumn{7}{|c|}{ Table 9: Consistency test for sub-criteria } \\
\hline G/TI & SR & PS & Priority vector(PV) & New vector(NV) & NV/PV \\
\hline SR & 1 & 3 & 0.750 & 1.500 & 2.000 \\
\hline PS & $1 / 3$ & 1 & 0.250 & 0.500 & 2.000 \\
\hline & & & & Total=4.000 & \\
\hline
\end{tabular}

Maximum eigenvalue $=2.000$ Consistency index $(\mathrm{Cl})=0.000$ Consistency ratio $(\mathrm{CR})=0.000$. 
Table 10: Consistency test for alternatives in context of BCS:

\begin{tabular}{|c|c|c|c|c|c|c|c|}
\hline Alternatives & M1 & M2 & M3 & M4 & Priority vector(PV) & New vector(NV) & NV/PV \\
\hline M1 & 1 & $1 / 3$ & $1 / 5$ & $1 / 5$ & 0.064 & 0.266 & 4.156 \\
\hline M2 & 3 & 1 & $1 / 3$ & $1 / 5$ & 0.122 & 0.512 & 4.196 \\
\hline M3 & 5 & 3 & 1 & $1 / 3$ & 0.271 & 1.136 & 4.191 \\
\hline M4 & 5 & 5 & 3 & 1 & 0.544 & 2.287 & 4.204 \\
\hline & & & & & & Total= 16.747 & \\
\hline
\end{tabular}

Maximum eigenvalue $=4.186$ Consistency index $(C I)=0.062$ Consistency ratio $(C R)=0.068$.

Table 11: Consistency test for alternatives in context of PC:

\begin{tabular}{|c|c|c|c|c|c|c|c|}
\hline Alternatives & M1 & M2 & M3 & M4 & Priority vector(PV) & New vector(NV) & NV/PV \\
\hline M1 & 1 & $1 / 3$ & 3 & 5 & 0.288 & 1.205 & 4.184 \\
\hline M2 & 3 & 1 & 3 & 5 & 0.505 & 2.118 & 4.194 \\
\hline M3 & $1 / 3$ & $1 / 3$ & 1 & 3 & 0.143 & 0.599 & 4.188 \\
\hline M4 & $1 / 5$ & $1 / 5$ & $1 / 3$ & 1 & 0.064 & 0.269 & 4.203 \\
\hline & & & & & & Total=16.769 \\
\hline
\end{tabular}

Maximum eigenvalue $=4.192$ Consistency index $(\mathrm{Cl})=0.064$ Consistency ratio $(\mathrm{CR})=0.071$.

\section{Table 12: Consistency test for alternatives in context of BE:}

\begin{tabular}{|c|c|c|c|c|c|c|c|}
\hline Alternatives & M1 & M2 & M3 & M4 & Priority vector(PV) & New vector(NV) & NV/PV \\
\hline M1 & 1 & 1 & $1 / 3$ & $1 / 3$ & 0.127 & 0.525 & 4.133 \\
\hline M2 & 1 & 1 & $1 / 3$ & 1 & 0.162 & 0.674 & 4.160 \\
\hline M3 & 3 & 3 & 1 & 3 & 0.487 & 2.023 & 4.154 \\
\hline M4 & 3 & 1 & $1 / 3$ & 1 & 0.223 & 0.928 & 4.161 \\
\hline & & & & & & Total=16.608 & \\
\hline
\end{tabular}

Maximum eigenvalue $=4.152$ Consistency index $(C I)=0.050$ Consistency ratio $(C R)=0.056$.

\begin{tabular}{|c|c|c|c|c|c|c|c|}
\hline \multicolumn{8}{|c|}{ Table 13: Consistency test for alternatives in context of EX: } \\
\hline Alternatives & M1 & M2 & M3 & M4 & Priority vector(PV) & New vector(NV) & NV/PV \\
\hline M1 & 1 & 3 & 3 & 5 & 0.523 & 2.155 & 4.120 \\
\hline M2 & $1 / 3$ & 1 & 3 & 3 & 0.263 & 0.476 & 4.114 \\
\hline M3 & $1 / 3$ & $1 / 3$ & 1 & 1 & 0.116 & 0.406 & 4.103 \\
\hline M4 & $1 / 5$ & $1 / 3$ & 1 & 1 & 0.099 & Total=16.438 & 4.101 \\
\hline & & & & & & \\
\hline
\end{tabular}

Maximum eigenvalue $=4.109$ Consistency index $(\mathrm{Cl})=0.036$ Consistency ratio $(\mathrm{CR})=0.040$.

Table 14: Consistency test for alternatives in context of PR:

\begin{tabular}{|c|c|c|c|c|c|c|c|}
\hline Alternatives & M1 & M2 & M3 & M4 & Priority vector(PV) & New vector(NV) & NV/PV \\
\hline M1 & 1 & 1 & 3 & 1 & 0.303 & 1.260 & 4.158 \\
\hline M2 & 1 & 1 & 3 & 3 & 0.389 & 1.616 & 4.154 \\
\hline M3 & $1 / 3$ & $1 / 3$ & 1 & 1 & 0.130 & 0.538 & 4.138 \\
\hline M4 & 1 & $1 / 3$ & 1 & 1 & 0.178 & 0.740 & 4.157 \\
\hline & & & & & & Total=16.607 \\
\hline
\end{tabular}

Maximum eigenvalue $=4.151$ Consistency index $(\mathrm{Cl})=0.050$ Consistency ratio $(\mathrm{CR})=0.055$. 
Table 15: Consistency test for alternatives in context of UN:

\begin{tabular}{|c|c|c|c|c|c|c|c|}
\hline Alternatives & M1 & M2 & M3 & M4 & Priority vector(PV) & New vector(NV) & NV/PV \\
\hline M1 & 1 & $1 / 3$ & 1 & 1 & 0.175 & 0.727 & 4.154 \\
\hline M2 & 3 & 1 & 3 & 1 & 0.409 & 1.700 & 4.156 \\
\hline M3 & 1 & $1 / 3$ & 1 & 1 & 0.175 & 0.727 & 4.154 \\
\hline M4 & 1 & 1 & 1 & 1 & 0.241 & 1.000 & 4.149 \\
\hline & & & & & & Total=16.613 \\
\hline
\end{tabular}

Maximum eigenvalue $=4.153$ Consistency index $(C I)=0.051$ Consistency ratio $(C R)=0.056$.

\section{Table 16: Consistency test for alternatives in context of CO:}

\begin{tabular}{|c|c|c|c|c|c|c|c|}
\hline Alternatives & M1 & M2 & M3 & M4 & Priority vector(PV) & New vector(NV) & NV/PV \\
\hline M1 & 1 & 1 & 5 & 3 & 0.413 & 1.663 & 4.026 \\
\hline M2 & 1 & 1 & 3 & 3 & 0.360 & 1.451 & 4.030 \\
\hline M3 & $1 / 5$ & $1 / 3$ & 1 & 1 & 0.106 & 0.428 & 4.037 \\
\hline M4 & $1 / 3$ & $1 / 3$ & 1 & 1 & 0.120 & 0.483 & 4.025 \\
\hline & & & & & & Total=16.118 \\
\hline
\end{tabular}

Maximum eigenvalue $=4.029$ Consistency index $(\mathrm{Cl})=0.009$ Consistency ratio $(\mathrm{CR})=0.010$.

\section{Table 17: Consistency test for alternatives in context of FX:}

\begin{tabular}{|c|c|c|c|c|c|c|c|}
\hline Alternatives & M1 & M2 & M3 & M4 & Priority vector(PV) & New vector(NV) & NV/PV \\
\hline M1 & 1 & 7 & 3 & 3 & 0.574 & 2.348 & 4.090 \\
\hline M2 & $1 / 7$ & 1 & 1 & 1 & 0.124 & 0.508 & 4.096 \\
\hline M3 & $1 / 3$ & 1 & 1 & 1 & 0.151 & 0.617 & 4.086 \\
\hline M4 & $1 / 3$ & 1 & 1 & 1 & 0.151 & 0.617 & 4.086 \\
\hline & & & & & & Total=16.358 & \\
\hline
\end{tabular}

Maximum eigenvalue $=4.089$ Consistency index $(C I)=0.029$ Consistency ratio $(C R)=0.032$.

Table 18: Consistency test for alternatives in context of MO:

\begin{tabular}{|c|c|c|c|c|c|c|c|}
\hline Alternatives & M1 & M2 & M3 & M4 & Priority vector(PV) & New vector(NV) & NV/PV \\
\hline M1 & 1 & 1 & 3 & 5 & 0.425 & 1.746 & 4.108 \\
\hline M2 & 1 & 1 & 1 & 3 & 0.282 & 1.160 & 4.113 \\
\hline M3 & $1 / 3$ & 1 & 1 & 3 & 0.213 & 0.876 & 4.112 \\
\hline M4 & $1 / 5$ & $1 / 3$ & $1 / 3$ & 1 & 0.080 & 0.330 & 4.125 \\
\hline & & & & & & Total=16.458 & \\
\hline
\end{tabular}

Maximum eigenvalue $=4.114$ Consistency index $(\mathrm{Cl})=0.038$ Consistency ratio $(\mathrm{CR})=0.042$.

\begin{tabular}{|c|c|c|c|c|c|c|c|}
\hline \multicolumn{9}{|c|}{ Table 19: Consistency test for alternatives in context of SR: } \\
\hline Alternatives & M1 & M2 & M3 & M4 & Priority vector(PV) & New vector(NV) & NV/PV \\
\hline M1 & 1 & 1 & 3 & 5 & 0.412 & 1.697 \\
\hline M2 & 1 & 1 & 1 & 5 & 0.310 & 0.210 & 0.864 \\
\hline M3 & $1 / 3$ & 1 & 1 & 3 & 4.114 & 0.069 & 4.101 \\
\hline M4 & $1 / 5$ & $1 / 5$ & $1 / 3$ & 1 & & & 0.283 \\
\hline
\end{tabular}

Maximum eigenvalue $=4.113$ Consistency index $(\mathrm{Cl})=0.037$ Consistency ratio $(\mathrm{CR})=0.041$. 


\begin{tabular}{|c|c|c|c|c|c|c|c|}
\hline \multicolumn{8}{|c|}{ Table 20: Consistency test for alternatives in context of PS: } \\
\hline Alternatives & M1 & M2 & M3 & M4 & Priority vector(PV) & New vector(NV) & NV/PV \\
\hline M1 & 1 & 3 & 3 & 5 & 0.513 & 2.110 & 4.113 \\
\hline M2 & $1 / 3$ & 1 & 1 & 5 & 0.226 & 0.930 & 4.115 \\
\hline M3 & $1 / 3$ & 1 & 1 & 3 & 0.193 & 0.794 & 4.113 \\
\hline M4 & $1 / 5$ & $1 / 5$ & $1 / 3$ & 1 & 0.068 & Total=16.443 & 4.102 \\
\hline
\end{tabular}

Maximum eigenvalue $=4.110$ Consistency index $(C I)=0.036$ Consistency ratio $(C R)=0.040$.

\begin{tabular}{|c|c|c|c|c|c|c|c|c|c|c|c|}
\hline \multicolumn{12}{|c|}{ Priority vector/eigen vector Goal } \\
\hline \multirow{2}{*}{$\begin{array}{c}\text { Criteria } \\
\text { Sub- } \\
\text { criteria }\end{array}$} & \multicolumn{4}{|c|}{ MI } & \multicolumn{2}{|c|}{ os } & \multicolumn{3}{|c|}{ VI } & \multicolumn{2}{|c|}{$\mathrm{TI}$} \\
\hline & BCS & $\mathrm{PC}$ & BE & EX & PR & UN & $\mathrm{CO}$ & $\mathrm{FX}$ & MO & SR & PS \\
\hline M1 & 0.064 & 0.288 & 0.127 & 0.523 & 0.303 & 0.175 & 0.413 & 0.574 & 0.425 & 0.412 & 0.513 \\
\hline M2 & 0.122 & 0.505 & 0.162 & 0.263 & 0.389 & 0.409 & 0.360 & 0.124 & 0.282 & 0.310 & 0.226 \\
\hline M3 & 0.271 & 0.143 & 0.487 & 0.116 & 0.130 & 0.175 & 0.106 & 0.151 & 0.213 & 0.210 & 0.193 \\
\hline M4 & 0.544 & 0.064 & 0.223 & 0.099 & 0.178 & 0.241 & 0.120 & 0.151 & 0.080 & 0.069 & 0.068 \\
\hline \multicolumn{12}{|c|}{ Consistency test } \\
\hline$\lambda_{\max }$ & 4.186 & 4.192 & 4.152 & 4.109 & 4.151 & 4.153 & 4.029 & 4.089 & 4.114 & 4.113 & 4.113 \\
\hline $\mathrm{Cl}$ & 0.062 & 0.064 & 0.050 & 0.036 & 0.050 & 0.051 & 0.009 & 0.029 & 0.038 & 0.037 & 0.036 \\
\hline $\mathrm{RI}$ & 0.9 & & & & & & & & & & \\
\hline CR & 0.068 & 0.071 & 0.056 & 0.040 & 0.055 & 0.056 & 0.010 & 0.032 & 0.042 & 0.041 & 0.040 \\
\hline
\end{tabular}

\section{Table 22: All priority vectors for criteria, sub-criteria and alternatives}

\begin{tabular}{|c|c|c|c|c|c|c|c|c|c|c|c|}
\hline \multicolumn{12}{|c|}{$\begin{array}{l}\text { Priority vector/eigen vector } \\
\text { Goal }\end{array}$} \\
\hline \multirow{2}{*}{$\begin{array}{c}\text { Criteria } \\
\text { Sub-criteria }\end{array}$} & \multicolumn{4}{|c|}{ MI (0.549) } & \multicolumn{2}{|c|}{ OS (0.248) } & \multicolumn{3}{|c|}{ VI (0.129) } & \multicolumn{2}{|c|}{$\mathrm{TI}(0.074)$} \\
\hline & BCS & PC & $\mathrm{BE}$ & EX & PR & UN & $\mathrm{CO}$ & FX & MO & SR & PS \\
\hline & 0.508 & 0.151 & 0.265 & 0.075 & 0.833 & 0.167 & 0.637 & 0.258 & 0.105 & 0.750 & 0.250 \\
\hline \multicolumn{12}{|l|}{ Alternatives } \\
\hline M1 & 0.064 & 0.288 & 0.127 & 0.523 & 0.303 & 0.175 & 0.413 & 0.574 & 0.425 & 0.412 & 0.513 \\
\hline M2 & 0.122 & 0.505 & 0.162 & 0.263 & 0.389 & 0.409 & 0.360 & 0.124 & 0.282 & 0.310 & 0.226 \\
\hline M3 & 0.271 & 0.143 & 0.487 & 0.116 & 0.130 & 0.175 & 0.106 & 0.151 & 0.213 & 0.210 & 0.193 \\
\hline M4 & 0.544 & 0.064 & 0.223 & 0.099 & 0.178 & 0.241 & 0.120 & 0.151 & 0.080 & 0.069 & 0.068 \\
\hline
\end{tabular}

\section{Develop overall priority ranking}

The priority vectors for criteria, sub-criteria and alternatives are shown in Table 22. The priorities of the criteria, Method Information (MI), Operation Skill (OS), Viability (VI), and Technical Information (TI), are 0.549, 0.248, 0.129 , and 0.074 respectively. The priorities of the sub criteria, BCS Classification of drugs(BCS), Processing conditions (PC), Benefits(BE), Expenditure(EX), Performance(PR), Understanding(UN), Consistency(CO), Flexibility(FX), Monotonous(MO), Size reduction(SR) and Processing steps(PS) are 0.508, 0.151, 0.265, $0.075,0.833,0.167,0.637,0.258,0.105,0.750$ and 0.250 respectively. 
The overall priority vector for four alternative methods with respect to the sub-criteria are shown in Table 23. By multiplying the priority vector for the alternative methods with priority vector of the sub-criteria, overall priority vector can be obtained. For instance overall priority is calculated as:

$0.064(0.508)+0.288(0.151)+0.127(0.265)+$ $0.523(0.075)=0.147$.

The overall priority vector of the alternatives with respect to the criteria are shown in Table 24 . By multiplying the priority vector for the alternative methods with priority vector of the criteria, overall priority vector can be obtained. For instance overall priority is calculated as: $0.147(0.549)+0.281(0.248)+0.455(0.129)+$ $0.074(0.437)=0.239$.

\section{Selection of most suitable method}

The selection of best method is done based on the final ranking of the alternatives. By using AHP technique in this study, a hierarchy was designed containing the decision as goal, the alternatives for reaching it and the criteria for evaluating the alternatives and subcriteria for evaluating the criteria. Based on the results obtained as shown in Table 25 the method M2 Sonoprecipitation method scored 0.263 , M4 Nanomorph ${ }^{\circledR}$ method scored 0.258, M1 Hydrosol method scored 0.239 and finally M3 Spray freezing into liquid (SFL) method scored 0.225. As per Saaty the alternative with the highest priority would be the most suitable method. ${ }^{18}$ So alternative with highest priority is method M2, Sonoprecipitation method scoring 0.263 which is highest compared to other alternatives. Hence having worked out the AHP technique, the Sonoprecipitation method is judged to be the most suitable method for the preparation of nanocrystals.

\section{CONCLUSION}

This paper presents the method of selecting the most appropriate method for preparation of nanocrystals by implementing the analytic hierarchy process (AHP). AHP is very helpful for the designers to select the best method based on the criteria and sub-criteria aspects of a decision. The study reveals that Method 2, the Sonoprecipitation method is the most suitable method for the preparation of nanocrystals as per Saaty, because it has the highest value $(0.263$ or $26.3 \%$ ) compared to any of the methods. The application of the AHP for selecting the most apt method for the preparation of nanocrystals can advance the quality of the product and shorten the product improvement process. In this paper, AHP has been employed to capture the decision making process to provide reliable and efficient decision.

\begin{tabular}{|l|l|l|l|l|}
\hline \multicolumn{5}{|c|}{ Table 23: Overall priority vectors for alternatives } \\
with respect to sub-criteria \\
\hline M1 & 0.147 & 0.281 & 0.455 & 0.437 \\
\hline M2 & 0.198 & 0.392 & 0.289 & 0.288 \\
\hline M3 & 0.295 & 0.137 & 0.127 & 0.205 \\
\hline M4 & 0.351 & 0.188 & 0.122 & 0.068 \\
\hline
\end{tabular}

\begin{tabular}{|c|c|c|c|c|c|}
\hline \multicolumn{6}{|c|}{ Table 24: Overall priority vectors for alternatives with } \\
respect to criteria \\
\cline { 1 - 5 } & MI & OS & VI & TI & \multirow{2}{*}{$\begin{array}{l}\text { Overall } \\
\text { Priority }\end{array}$} \\
\cline { 2 - 5 } & $\mathbf{0 . 5 4 9}$ & $\mathbf{0 . 2 4 8}$ & $\mathbf{0 . 1 2 9}$ & $\mathbf{0 . 0 7 4}$ & \\
\hline M1 & 0.147 & 0.281 & 0.455 & 0.437 & 0.239 \\
\hline M2 & 0.198 & 0.392 & 0.289 & 0.288 & 0.263 \\
\hline M3 & 0.295 & 0.137 & 0.127 & 0.205 & 0.225 \\
\hline M4 & 0.351 & 0.188 & 0.122 & 0.068 & 0.258 \\
\hline
\end{tabular}

\begin{tabular}{|c|c|c|}
\hline \multicolumn{3}{|c|}{ Table 25: Result of selection: } \\
\hline S. No & Best Selection & Overall Priority \\
\hline 1 & M2 & 0.263 \\
\hline 2 & M4 & 0.258 \\
\hline 3 & M1 & 0.239 \\
\hline 4 & M3 & 0.225 \\
\hline
\end{tabular}

Hence we can obtain consistent and best preferred decision easily and efficiently by using this tool.

\section{ACKNOWLEDGMENT}

We express our sincere thanks to UGC-BSR for providing us fellowship to carry out the research work. We wish to thank Dr.C.Antony Jeyasekar, DEAN, Faculty of Engineering and technology and also Dr.P.K.Manna, Head of department, Department of pharmacy for their assistance during this study. We are also thankful to Dr.K.Kannan for helping in the preparation and proof reading of this manuscript.

\section{CONFLICT OF INTEREST}

The authors declare no conflict of interest.

\section{ABBREVIATIONS USED}

API: Active pharmaceutical ingredient; AHP: Analytic Hierarchy Process; MI: Method Information; OS: Operational Skill; VI: Viability; TI: Technical Information; BCS: Biopharmaceutical Classification system; PC: Processing conditions; BE: Benefits; EX: Expenditure; PR: Performance; UN: Understanding; CO: 
Consistency; FX: Flexibility; MO: Monotonous; SR: Size reduction; PS: Processing steps; M: alternative methods; CR: Consistency ratio; CI: Consistency index; RI: random index; $\lambda_{\text {max }}:$ Eigenvalue; SFL: Spray freezing into liquid; M1: Hydrosol; M2: Sonoprecipitation; M3: Spray freezing into liquid; M4: Nanomorph ${ }^{\circledR}$.

\section{REFERENCES}

1. Zhang L, Webster, TJ. Nanotechnology and Nano materials, Promises for Improved Tissue Regeneration. Nano Today. 2009;4:66-80. https://doi. org/10.1016/j.nantod.2008.10.014.

2. Keck CM, Muller RH. Drug Nanocrystals of poorly soluble Drug products by High Pressure Homogenisation. Eur J Pharm and Biopharm. 2006;62:3-16. https://doi.org/10.1016/j.ejpb.2005.05.009 PMid:16129588.

3. Tugba G, Neslihan G R, Levent O. Nanocrystal Technology for Oral Delivery of Poorly Water-Soluble Drugs. FABAD J Pharm Sci. 2009;34:55-65.

4. Mitali K, Ranjita S, Nanda G S, Sven G, Lin Li, Rainer. H Muller. Longterm stability of quercetin nanocrystals prepared by different methods. Journal of Pharmacy and Pharmacology. 2012;64(10):1394-402. https://doi. org/10.1111/j.2042-7158.2012.01515.x PMid:22943170.

5. Grant DJW, Brittan HG. Physical characterisation of pharmaceutical solids. In Britton HG (ed). Marcel Dekker, New York. 1995.

6. Rabinow B.E. Nanosuspensions in drug delivery. Nat Rev Drug Discov. 2004;3(9):785. https://doi.org/10.1038/nrd1494 PMid:15340388.

7. Moschwitzer J.P. Drug nanocrystals in the commercial pharmaceutical development process. Int J Pharm. 2013;453(1):142-56. https://doi. org/10.1016/j.jpharm.2012.09.034 PMid:23000841.

8. Junghanns J.U, Muller R.H. Nanocrystal technology, drug delivery and clinical applications. Int J Nanomed. 2008;3:295-309. PMid:18990939 PMCid:PMC2626933.

9. Raghava S K.M, Mishra B. Drug nanocrystals: a way toward scale-up. Saudi Pharm. J. 2014.

10. Jinno J, Kamada N, Miyake M, Yamada K, Mukai T, Odomi M, Toguchi H, Liversidge G G, Higaki K, Kimura T. Effect of hydrodynamic diameter reduction on dissolution and oral absorption of a poorly water-soluble drug cilostazol in beagle dogs. J Control Release. 2006;111(1):56-64. https://doi. org/10.1016/j.jconrel.2005.11.013 PMid:16410029.

11. Mengran G, Qiang F, Chunnuan W, Zhibin G, Mo L, Jin S, Zhonggui H, Li Y. Rod shaped nanocrystals exhibit superior in vitro dissolution and in vivo bioavailability over spherical like nanocrystals: A case study of lovastatin.
Colloids and Surfaces B: Biointerfaces. 2015;128:410-8. https://doi. org/10.1016/j.colsurfb.2015.02.039 PMid:25766921.

12. Tzu-Lan C, Honglei Z, Danni L, Jun F. L. Nanocrystal technology for drug formulation and delivery. Front Chem Sci Eng. 2015;9(1):1-14. https://doi. org/10.1007/s11705-015-1509-3.

13. George D, Franck PM, Francois R, Jerry YY H. Pharmaceutical nanocrystals Current Opinion in Chemical Engineering. 2012;1:102-7. https://doi. org/10.1016/j.coche.2011.12.001.

14. Sumit K, Xiaoming X, Rajeev G, Diane JB. Formulation parameters of crystalline nanosuspensions on spray drying processing: A DoE approach. International Journal of Pharmaceutics. 2014;464(1):34-45.

15. Annika T, Timo L, Johanna L, Osmo A, Juha K, Jukka I O O, Seppo R, Kristiina J, Jouni H, Leena P. Solid formulations by a nanocrystal approach: Critical process parameters regarding scale-ability of nanocrystals for tableting applications. International Journal of Pharmaceutics. 2015;485:77-86. https://doi.org/10.1016/j.ijpharm.2015.03.009 PMid:25746735.

16. Tzu-Lan C, Honglei Z, Danni L, Jun F. L. Nanocrystal technology for drug formulation and delivery. Front Chem Sci Eng. 2015;9(1):1-14. https://doi. org/10.1007/s11705-015-1509-3.

17. Moorthi C, Kathiresan K. Fabrication of Dual Drug Loaded Polymeric Nanosuspension: Incorporating Analytical Hierarchy Process and Data Envelopment Analysis in the Selection of a Suitable Method. Int J Pharm Pharm Sci. 2013;5(2):499-504.

18. Saaty T.L. The Analytic Hierarchy Process: Planning, Priority Setting, Resource Allocation. McGraw-Hill. 1980.

19. Velmurugan R, Selvamuthukumar S, Manavalan R. Multi criteria decision making to select the suitable method for the preparation of nanoparticles using an analytical hierarchy process. Pharmazie. 2011;66(11):836-42. PMid:22204128.

20. Saaty T L. "A scaling method for priorities in hierarchical structures". Journal of Mathematical Psychology. 1977;15:234-81. https://doi.org/10.1016/00222496(77)90033-5.

21. Kannan K, Manikandan M. Selection of a Suitable Method for the Preparation of Polymeric Nanoparticles: Multi-Criteria Decision Making Approach. Adv Pharm Bull. 2015;5(1);57-67.

22. Adhikari I, Kim SY, Lee YD. Selection of Appropriate Schedule Delay Analysis. 2006;483-8.

23. Cheng SC, Chen MY, Chang HY and Chou TZ. Semantic-based facial expression recognition using Analytical Hierarchy Process. J Expert Syst Applic. 2007;33:86-95. https://doi.org/10.1016/j.eswa.2006.04.019.

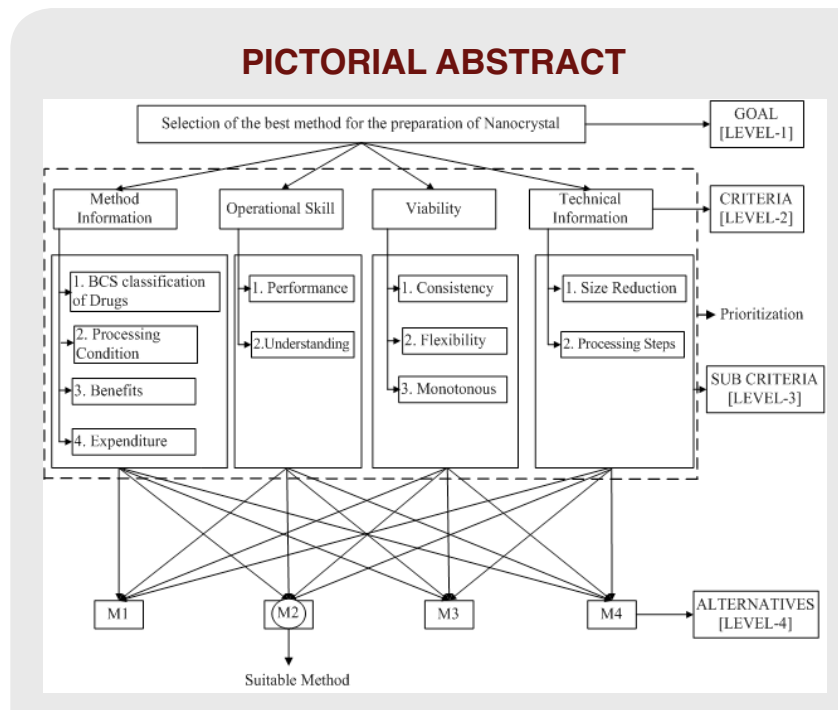

\section{SUMMARY}

- The purpose of this paper is to present a systematic approach for selecting the best method for the preparation of nanocrystals.

- The selection process is done by implementing the analytic hierarchy process.

- AHP is very helpful for the designers to select the best method based on the criteria and sub-criteria aspects of a decision.

- Hence having worked out the AHP technique, the Sonoprecipitation method is judged to be the most suitable method for the preparation of nanocrystals as per Saaty, because it has the highest value compared to any of the methods. So AHP has been employed to capture the decision making process to provide reliable and efficient decision. 


\section{About Authors}

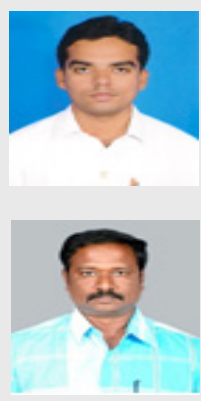

Mr. Venkatesh Kyavars: Currently I am pursuing Ph. D. degree in the Development of Nanocrystals as a delivery platform at Department of Pharmacy, Annamalai University, Annamalai Nagar, Chidambaram, Tamilnadu (India). I completed B. Pharm. in 2011 in Annamalai University \& M. Pharm (Pharmaceutics) in 2013 in Jawaharlal Nehru Technological University, Hyderabad (India).

Dr S. Selvamuthukumar: He has completed his Ph. D. degree in Pharmacy at the Dept. of Pharmacy, Annamalai University, Annamalai Nagar, Tamilnadu (India). Dr. S. Selvamuthukumar completed M. Pharm. with specialization in Industrial Pharmacy from the same University. He has published a number of papers in various peer reviewed journals in the field of Pharmaceutics and Nanotechnology

Cite this article: K Venkatesh and S Selvamuthukumar. Multi Criteria Decision Making to Select the Suitable Method for the Preparation of Nanocrystals Using an Analytic Hierarchy Process. Indian J of Pharmaceutical Education and Research. 2017;51(2):249-59. 